JOURNAL OF CORPORATE RESPONSIBILITY

AND LEADERSHIP

InNOVATIONS IN CORPORATE SOCIAL RESPONSIBILITY

and Public Management

\title{
Substance Use Disorders and Reintegration - A Novel Perspective on Empathy for Those in Need
}

DOI: http://dx.doi.org/10.12775/JCRL.2018.023

\section{Nina Szczygiel ${ }^{\mathrm{a}}$, Manuel Au-Yong-Oliveira ${ }^{\mathrm{b}}$}

The Research Unit on Governance, Competitiveness and Public Policies (GOVCOPP),

Department of Economics, Management, Industrial Engineering and Tourism,

The University of Aveiro, Portugal

a email: nina.szczygiel@ua.pt

b email: mao@ua.pt

\author{
Adriana Coutinho ${ }^{c}$, Andreia Rodrigues $^{\mathrm{d}}$, Rúben Lopes $^{\mathrm{e}}$ \\ Department of Economics, Management, Industrial Engineering and Tourism, \\ The University of Aveiro, Portugal \\ c email: adrianacoutinho@ua.pt \\ demail: andreiaraquel@ua.pt \\ e email: ruben.daniel@ua.pt
}

\begin{abstract}
Purpose: To analyse the reintegration and social responses addressing substance use disorders using a social responsibility approach. To evaluate perceptions of persons with substance use disorders in rehabilitation and opinions about their reintegration in the labour market.

Design/methodology/approach: Mixed methodology combining both qualitative and quantitative approaches, with the use of mini focus group interview and questionnaire survey.

Findings: Preconception about persons with substance-related disorders is considerable. At the same time, people are willing to accept individuals in treatment in the professional environment and to support them. Dental health problems are not only an image issue but constitute a major barrier in activities of daily living and hinder social integration. The financial aspect of social initiatives to be implemented needs to be recognised and addressed.
\end{abstract}


Research and practical limitations/implications: We show that programmes of reintegration of people with a past related to substance use disorders should in the first place focus on existing preconceptions. Cooperation with businesses for the professional reintegration of individuals in treatment for addictive behaviours and dependencies is vital for its success. Social initiatives need suitable dissemination and funding.

Originality/value: The paper deals with an important social problem. Social responses for individuals in treatment are very important but require additional societal awareness and business structures supporting social integration that are still to be worked on. These two features are prerequisites for any successful socio-professional reintegration.

Paper type: Case study, research paper.

Keywords: reintegration, substance use disorder, preconception, social responsibility.

\section{Introduction}

Individual choices can make people follow different paths and patterns. Less fortunate choices can lead to problematic life circumstances and very vulnerable conditions. The number of people with substance use disorders has not been rising over the last few years but remains substantial. For those who have recovered and who are still in rehabilitation, it is important to provide tools and create conditions fostering reintegration. Not only do these individuals need jobs, they need jobs which are right for them at the phase of life they are in, now. Furthermore, they need professional counselling, but often also to gain self-confidence and work on communication skills and even on their physical appearance. Social structures and responses in place should provide mechanisms of support tailored to fit individual needs. As social responses for social reintegration presume an interaction aiming to incorporate into social structures of society, their success depends on societal engagement and participation, and society becomes one of the key agents in the process of social reintegration. Public recognition, awareness and consciousness all contribute to the process. It becomes important to understand what people think about individuals in treatment for substance use disorders in the professional environment and what position the business arena has in adopting socially responsible approaches.

The study addresses a current social problem and brings insights on relevant aspects concerning the professional reintegration of individuals 
with substance use disorders. It provides perceptions of persons with substance use disorders and of the importance of physical appearance in the professional environment. We discuss existing social initiatives specifically directed at supporting the reintegration of people with substance use disorders with relevant factors contributing to or hindering reintegration of this specific group. This is the response regarding the social responsibility trend, which supports business approaches based on activism and the investing in, and addressing of, social matters.

The aim of this article is therefore to analyse the reintegration and social responses addressing substance use disorders using a social responsibility approach. We look closer at initiatives specifically addressing substance misuse. We evaluate perceptions of people with substance use disorders in rehabilitation and opinions about their reintegration in the labour market. We want to understand the most pressing concerns of those who need to be reintegrated within existing social initiatives.

We used a mixed methodology approach for this case study. We conducted a focus group with representatives of a local branch of the Red Cross in Portugal, Aveiro, in order to collect information about initiatives specifically aimed to support individuals with substance related disorders and their opinions about social issues of special relevance for that group. Next, we conducted an online survey in which we gathered views toward persons with addiction and their reintegration in the labour market.

The paper is organised as follows. Firstly, we present a background of the study that contextualizes our research. Secondly, we describe the methodology we used. Then, the results of the empirical study are presented. Finally, discussion and conclusions are provided.

\section{Background of the study}

Addiction is a disorder in which a person compulsively engages in harmful behaviours through rewarding stimuli regardless of adverse consequences. When an individual is experiencing an addiction, not only they feel they need to do something in order to function, the sensation is overwhelming and it lasts for a long time. Shopping, gaming, eating to the limit can all turn into a behaviour we cannot control. On the other hand, there are substances widely recognised as potentially 
dangerous to one's health. Illicit substances but also medications, tobacco and alcohol especially in the long term and in large doses can lead to dependence and have negative health-related consequences (UNESCO, 2017, p. 26).

About a quarter of a billion people used drugs in 2015 (UNODC, 2017, p. 9), the same as a year before (UNODC, 2017, p. ix). The World Drug Report 2017 estimates that 29.5 million drug users, that is 0.6 percent of the global population, suffer from substance use disorders (UNODC 2017, p. 9). Substance use disorders negatively affect individuals and their relatives because they severely shake-up the entire family and friends' cycle, contributing to social isolation which in turn makes the rehabilitation process even more difficult. Their impact spreads to the community, business and to society as a whole. They have been addressed as an important issue in public health and in the public policy agenda (Sumnall and Brotherhood 2012, pp. 13-25; Cheema et al., 2017, p. 309). Treatment comprises a combination of medication and counselling as parts of in- or out-patient residential care, recovery clinics, local support groups, care centres, or medical care, and ranges from tailored individual interventions to web-based programmes (Campbell et al., 2014, pp. 683-684). The process of recovery and reintegration is complex implying a total cut-off from other drug users, often the only social environment they have had for a long time.

The Handbook on Social Integration of Recovered Drug Users (Tripler Project, 2017, pp. 15-16) provides evidence from the initiatives of social reintegration of persons with substance use disorders. In the Spanish experience, the process of reintegration is structured in three phases. Together with an individual's decision to start the treatment, work in phase 1 focuses on motivation and modification of behaviours. Phase 2 is a therapeutic phase in which an individual works on their autonomy, capacity of communication and identification with social values. It is supported by cognitive behavioural therapy, psychodynamic techniques and mindfulness. In phase 3, autonomy is the most significant and a person works towards integrating their social environment with personal characteristics.

Substance use disorders are preventable and treatable but a large proportion of individuals do not seek help. First, it is believed that drugs weaken free will (Vonasch, Clark, Lau, Vohs and Baumeister, 2017, pp. 55-58). For an individual, it is very difficult to quit on their own because of a solid biological component to dependency. Another reason 
is social stigma often associated to substance disorders. Such a disorder is seen as a voluntary option rather than a consequence of other circumstances. Evidence shows this is not necessarily the case (Oetting and Lynch, 2006, pp. 101-119; Robertson, David and Rao, 2003, pp. 6-11). Sajjadi, Harouni and Sani (2015, pp. 367-372) argue that drug disorders are complex phenomena and interventions require a view into personal, family and environmental backgrounds. At the same time, despite a public recognition of the problem existing, recovery programs regularly lack funding and health care systems tend to focus on acute care and not on prevention (Pullen and Oser, 2014, pp. 895-900).

Due to stigma and preconceptions about drug users the treatment for substance use disorders and rehabilitation are controversial. This stigma is grounded on a misunderstanding of who drug users are and what the nature of substance use is. Not only is the rehabilitation process slow but rehabilitation in society takes time and requires a different approach. Buchanan (2004, pp. 392-393) suggests that what these individuals actually need is integration and not reintegration as they have never had the necessary conditions to lead a normal life.

Business and society both play an important role in the reintegration process, the first by its socially responsible activities, the latter by means of attitudes, empathy and acceptance. Businesses have been working together with local communities toward a sustainable future society and a better quality of life. Doing business nowadays entails profitable management but also requires assuming the responsibility for actions taken toward the people with whom and around whom the company operates (Fitzgerald and Cormack, 2006, pp. 5-6). The challenge for contemporary businesses is to remain competitive and sustainable while protecting the planet and people. The agenda of social responsibility comprises activities not specifically required by law and that go beyond the economic interest of the company (Godfrey and Hatch, 2007, pp. 87-88). By addressing issues that are socially relevant, companies show people matter to them.

The Red Cross is an international humanitarian institution founded to protect life and health and to prevent and alleviate human suffering. It is based on the principles of neutrality, impartiality, humanity, independence, unity, voluntary service and universality (International Committee of the Red Cross, 2008, pp. 519-520). Disadvantaged and vulnerable groups are of special interest to the institution. The Portuguese Red Cross has 170 local structures spread throughout the 
country, one of which is based in Aveiro. Volunteers are responsible for most of the work done by the organisation.

The Red Cross has been present in Aveiro since 1870. It works in the area of psychological and social support, nutrition (Missão Sorriso, Portugal +Feliz), social emergency such as homelessness, absence or loss of autonomy, domestic violence, minors in danger (LNES) and emergency and rescue in situations that threaten life. Currently, the organisation is involved in two major projects: the Revive+ Project (project of social entrepreneurship that aims to support prison convicts in their reintegration into society) and the RIS Project intended to support persons in treatment for substance use disorders. The RIS Project consists of a range of activities and interventions for social reintegration. The initiative aims to create conditions for facilitating communication between individuals with CAD - addictive and dependency behaviours [comportamentos aditivos e dependências] and their families and networks, increasing personal and social skills, and involving the community in the process of social reintegration. It started in 2008 and two-year applications have since then been accepted. The last concluded phase was between February 2016 and February 2018. It is hoped the project can be extended, continued or even included in the regular activity of the organisation.

\section{Methodology}

We used a mixed methods approach. First, we conducted a mini focus group with two representatives of the Red Cross in Aveiro. Focus groups depend on a friendly environment where participants can openly discuss the problem (Dawson, Manderson and Tallo, 1993, p. 53). The two participants were a psychologist and a social worker, both of them employees of the Red Cross and with extensive knowledge about the organisation.

The focus group session followed a script with previously defined broad topics for discussion based on a literature review. The topics were:

(1) What is the area of activity of the Red Cross delegation in Aveiro? 
(2) Has the Red Cross in Aveiro already had any type of relationship with any companies in the region?

(3) What more could companies do in order to help combat social problems?

(4) What is the most urgent social need?

(5) Does the Red Cross have ideas about how companies could help address this need?

Issues discussed in more detail during the focus group were based on concrete and anonymous cases that the Red Cross had been monitoring as well as on the work developed by the institution (with an emphasis on the RIS Project - Rehabilitation and social insertion of individuals with CAD). The focus group was held in October 2017 and had a duration of 30 minutes. During the session, the interviewers took notes, which were then verified by the interviewees, who authorised their use for scientific purposes. The notes were transcribed and analysed. The outcome of the focus group was clear and it was not necessary to hold an additional session. The focus group provided valuable insights for the second step of the study.

The focus group we had conducted allowed us to have a better understanding of the reality of reintegration and of the challenges that people with substance use disorders might face. This knowledge, together with information from the literature review resulted in constructing of a short, four-item questionnaire that we used in a survey conducted between October and November 2017. We collected socio-demographic data on age, gender, profession and location. Through this method, we wanted to analyse the perceptions of these persons and also linked to the importance of physical appearance in the labour market. The questions assessed preconceptions about persons with substance use disorders and a belief in their rehabilitation, the reaction to finding one such a colleague in treatment on substance use disorder, and the importance of physical appearance in the job market. The questionnaire was posted online. Data collection took 14 days. We collected 354 valid responses in the survey. Female respondents comprised more than three quarters of the sample (78.0\%). The respondents were mostly students (59.6\%), from 18-25 years old (64.4\%), from the Central Region of Portugal (51.1\%). We used simple statistical procedures to analyse the data. 


\section{Results}

\subsection{Reintegration of individuals with substance use disorders in the labour market}

Preconceptions about individuals with substance use disorders are common and this is supported by the results of our study. This is the opinion of $96.6 \%$ of the respondents of our survey. At the same time, respondents would not mind accepting such persons in the professional environment (95.8\% of the sample), and would try to help and treat them the same as all other colleagues. The findings from the focus group also indicate that reintegration should ideally be gradual. A preferable placement is in factories because monotonous, repetitive jobs reduce work-related stress.

A number of companies actively collaborate with the Red Cross within the RIS Project and receive persons with substance use disorders in rehabilitation. Our results suggest that more businesses are needed to support the initiative. To support social initiatives, companies need to be more aware and receptive in receiving individuals in treatment. Specific training is found to be a good way for companies to increase their knowledge and for them to correct misconceptions and existing stigma, enabling them to work more effectively with this social group. Persons in treatment for addictive behaviours and dependencies linked to substance use are perceived as difficult, especially concerning the establishment of trusting relationships. Their functions such as memory, attention, concentration, speed of information processing, decision making and consequence assessment may have been compromised because of consumption. Their lack of control may be perceived by the employer as indicative of an incapacity to be relied on as concerns business-related matters. It is therefore vital to create mechanisms to connect with businesses on a regular basis in order to address this problem and battle preconceptions.

The Institute for Employment and Vocational Training (IEFP) has been promoting and implementing specific measures to support socio-professional reintegration. These measures are intended to involve the community, especially enterprises (Council of Ministers, 1998). With this in mind, the Life-Employment Programme was approved in 1998, and interrupted when the much-publicized 
austerity policies (circa 2011) were implemented in Portugal. The programme aims to promote socio-professional integration through internships of a maximum of nine months with the possibility of an additional three-month period (Pinto, 2017). Finally, non-financial support for trainees is a way to allow them to build stability (Mendes et al., 2014, pp. 23-25).

A number of other support initiatives in the context of substance use prevention were affected by the crisis. The programme of syringe exchange was moved from pharmacies to ACES (groups of primary care centres) limiting the availability of sterilised material, considered by the World Health Organisation as crucial in the battle against HIV. Social support, fundamental for the effectiveness of the response, was withdrawn. The measures also affected the key agent responsible for intervention in this field - the Institute for Drugs and Drug Addiction (Pinto, 2017). In spite of an increasing interest, the number of State initiatives to support this social cause is currently very limited. Therefore, the reactivation and dissemination of the Life-Employment Programme is one of the ways that companies have to respond to this important problem.

Companies nowadays have been seeking to collaborate with social partners (Bush, Grayson, Jordan and Nelson, 2008, pp. 3-8). Consumers like and value companies that are active in the community and that invest a part of their capital to help those in need. Community involvement has a positive impact on business and consumers (Hansen and Spitzeck, 2011, pp. 415-422). In the case of this specific issue, companies are seen as partners in combating prejudice, an issue highly valued by society.

\subsection{Dental health issues and reintegration in the labour market}

The labour market imposes strict standards of physical appearance (Liu and Sierminska, 2014, pp. 4-7; Mahajan, 2007, p.165). In our study, $75.4 \%$ of the surveyed population considered physical appearance in the labour market as important compared to 3.1\% who did not find it important. Physical appearance is thus seen to be an important component of the total evaluation of an individual seeking employment. Persons with substance-related disorders may find this especially alarming as the consumption of substances has a significant impact on physical condition and appearance. 
One of the generally acknowledged physical problems associated with the consumption of illicit substances and alcohol is tooth decay. Dental health problems cause embarrassment in personal relationships and are a source of possible prejudice (Brondani, Alan and Donnelly, 2017). This factor interferes with self-esteem especially in persons with CAD (Tripler Project 2017, p. 24) and turns into one of the greatest impediments to reintegration in the labour market. Self-esteem has been found to foster physical and mental health (Mann, Hosman, Schaalma and De Vries, 2004, p. 358) and to contribute to perceived quality of life (Kermode and McLean, 2001, pp. 36-39). Self-esteem drives personal aspirations and makes people determined, persistent and able to speak up when needed. Secondly, problems with dental care affect daily life activities, including food intake, constraining a healthy and balanced diet. For instance, one of the cases accompanied by the Red Cross in Aveiro and mentioned during the focus group involves a 26-year-old man who bases his nutrition on cereal flakes as he cannot ingest other types of food due to broken teeth. According to the information from the session, the current number of persons in treatment is above 70 .

The biggest obstacle to dental rehabilitation is that dental care treatments can reach high monetary sums, which are impossible to support by an individual. The estimated average value per patient is around 500 euros, in which the final cost depends on the clinic and on the individual needs of the patient. It becomes clear that the financial aspect is a central issue in solving this particular problem.

\section{Discussion and conclusions}

The use of substances has been stabilising over recent years but the numbers are still alarming. In 2015, 20.8 million people aged 12 or more met criteria for a substance use disorder (U.S. Department of Health and Human Services, 2016, pp. 36-45). The consumption has been found to be more frequent in males aged 15-34 (SICAD, 2015, pp. 23-24).

Substance use disorder is a medical condition. Discriminative practices and preconceptions hamper social reintegration. According to the report by the Commission for the National Anti-Drug Strategy (ENCD), "one cannot speak about success of a treatment program 
without the social reintegration of the drug addict, particularly in the professional field" (Commission for the ENCD, 1998, p. 80).

The findings of our study suggest that preconceptions about persons with substance-related disorders in Portugal are substantial. However, our survey also revealed that people harbour positive perspectives in relation to working with individuals in treatment and are willing to help. In addition, we find that support from the State is very attractive for companies albeit not sufficiently disseminated. Training for companies is fundamental for building empathy, understanding and mutual trust.

These aforementioned results are interesting in light of the existing literature. Previous research from the Johns Hopkins Bloomberg School of Public Health has found that in general there is no support for public policies, including employment policies, directed at helping people with substance use disorders. This large study has found that people are more likely to express negative opinions about persons with substance addiction than those with mental illness. For example, $22 \%$ of the respondents said that they would not mind working closely on a job with a person with drug addiction as compared to $62 \%$ of the respondents who would not mind working closely with someone with mental illness (Barry, McGinty, Pescosolido and Goldman, 2014, pp. 1270-1271). Evidence from Ireland suggests people are fearful of individuals with a diagnosed substance use disorder. It has also been found that younger people are less likely to avoid those with substance misuse problems in social relationships (Bryan, Moran, Farrell and O’Brien 2000, pp. 29-31). This finding might be particularly useful in explaining the results of our study in which a greater part of the respondents were youths.

This research has analysed social initiatives of the Red Cross directed specifically to address the problem of substance use disorders. We have tried to understand what conditions enhance and hinder the professional integration of this specific group. At the individual level, image-related issues appear to be of great importance, which is not surprising given its relevance to the general public. The most urgent social need has been found to be dental health issues, a problem widely associated with the consumption of substances. Given the scope and the cost it may reach, the problem cannot be solved by the person on their own. We have found that despite widespread preconceptions about people with substance-related disorders, people 
hold a positive perception concerning individuals in treatment and are open to accepting them in the professional environment. There are a number of State initiatives in place supporting integration but they seem to be lacking a suitable dissemination, the aspect requiring immediate action. At the organisational level, it would be important to implement continuous training for companies in order to address existing preconceptions and to create working environments built on mutual understanding and empathy. At the policy level, the key issue is to ensure that the information about existing support measures is properly disseminated and reaches the interested publics. Future works might focus on the evaluation of strategies aimed to tackle the socio-professional reintegration of individuals with substance use disorders at the national level or in the specific business context.

There is still a long and winding path for the effective rehabilitation and reintegration of persons with substance use disorders in Portugal. It is essential to take advantage of feelings of solidarity and empathy that have become an important force in the business arena.

\section{References}

Barry, C.L., McGinty, E.E., Pescosolido, B.A., Goldman, H.H. (2014), “Stigma, Discrimination, Treatment Effectiveness, and Policy: Public Views About Drug Addiction and Mental Illness”, Psychiatric Services, Vol. 65, No.10, pp. 1269-1272.

Brondani, M.A., Alan, R., Donnelly, L. (2017), “Stigma of Addiction and Mental Illness in Healthcare: The Case of Patients' Experiences in Dental Settings”, PLoS ONE, Vol.12, No. 5, e0177388.

Bryan, A., Moran, R., Farrell, E., O’Brien, M. (2000), Drug-Related Knowledge, Attitudes and Beliefs in Ireland: Report of a Nation-Wide Survey, The Health Research Board, Dublin.

Buchanan, J. (2004), “Missing Links? Problem Drug Use and Social Exclusion”, Probation Journal, Vol. 51, No. 4, pp. 387-397.

Bush, G., Grayson, D., Jordan, A., Nelson, J. (2008), Engaging Business in the Community: Not a Quick Fix, The Smith Institute. Retrieved from https://corporate-citizenship.com/wp-content/uploads/Engaging-Business-in-the-Community.pdf (accessed 1 May 2018).

Campbell, A.N., Nunes, E.V., Matthews, A.G., Stitzer, M., Miele, G.M., Polsky, D., Turrigiano, E., Walters, S., McClure, E.A., Kyle, T.L., Wahle, A., Van Veldhuisen, P., Goldman, B., Babcock, D., Quinn Stabile, P., Winhusen, T., Ghitza, U.E. (2014), "Internet-Delivered Treatment for Substance Abuse: A Multisite Randomized Controlled Trial”, American Journal of Psychiatry, Vol. 171, Issue 6, pp. 683-690. 
Cheema, S., Maisonneuve, P., Al-Thani, M.H., Al-Thani, A.A.M., Abraham, A., Al-Mannai, G.A., Al-Emadi, A.A., Al-Chetachi, W.F., Almalki, B.A., Khalifa, H.S.E., Haj Bakri A.O., Mamtani, R. (2017), “Oral Health Behavior and Factors Associated with Poor Oral Status in Qatar: Results from a National Health Survey”, Journal of Public Health Dentistry, Vol. 77, No. 4, pp. 308-316.

Commission for the ENCD (1998), National Anti-Drug Strategy.

Council of Ministers (1998), Resolução do Conselho de Ministros no. 136/98. Retrieved from https://dre.pt/application/file/a/222101 (accessed 28 April 2018).

Dawson, S., Manderson, L., Tallo, V.L. (1993), A Manual for the Use of Focus Groups, International Nutrition Foundation for Developing Countries, Boston. Fitzgerald, N., Cormack, M. (2006), The Role of Business in Society: An Agenda for Action, Prince of Wales International Business Leaders Forum. Retrieved from https://sites.hks.harvard.edu/m-rcbg/CSRI/publications/report_12_CGI\%20 Role\%20of\%20Business\%20in\%20Society\%20Report\%20FINAL\%20 10-03-06.pdf (accessed 25 July 2018).

Godfrey, P.C., Hatch, N.W. (2007), "Researching Corporate Social Responsibility: An Agenda for the 21 ${ }^{\text {st }}$ Century”, Journal of Business Ethics, Vol. 70, Issue 1, pp. 87-98.

Hansen, E.G., Spitzeck, H. (2011), "Measuring the Impacts of NGO Partnerships: The Corporate and Societal Benefits of Community Involvement”, Corporate Governance: The International Journal of Business in Society, Vol. 11, No. 4, pp. 415-426.

International Committee of the Red Cross (2008), Handbook of the International Red Cross and Red Crescent Movement, International Federation of Red Cross and Red Crescent Societies, Geneva.

Kermode, S., MacLean, D. (2001), "A Study of the Relationship between Quality of Life, Self-Esteem and Health”, Australian Journal of Advanced Nursing, Vol. 19, No. 2, pp. 33-40.

Liu, X., Sierminska, E. (2014), Evaluating the Effect of Beauty on Labor Market Outcomes: A Review of the Literature, Institute for the Study of Labor, Bonn.

Mahajan, R. (2007), “The Naked Truth: Appearance Discrimination, Employment, and the Law", Asian American Law Journal, Vol.14, pp. 165-203.

Mann, M.M., Hosman, C.M., Schaalma, H.P., De Vries, N.K. (2004), “Self-Esteem in a Broad-Spectrum Approach for Mental Health Promotion”, Health Education Research, Vol. 19, No. 4, pp. 357-372.

Mendes, F. and Associates (2014), Guia de Medidas de Apoio à Contratação. Retrieved from http://www.fredericomendes.pt/files/3713/9178/9658/Guia_ de_Medidas_de_Apoio_Contratao.pdf (accessed 29 April 2018).

Oetting, E.R., Lynch R.R. (2006), "Peers and the Prevention of Adolescent Drug Use”, in: Sloboda, Z. and Bukoski, W.J. (Eds.), Handbook of Drug Abuse Prevention: Theory, Science and Practice, Springer, pp. 101-121.

Pinto, M. (2017), Evite-se um Erro Crasso na Política de Drogas deste País. Público. Retrieved from https:/www.publico.pt/2017/06/22/sociedade/opiniao/ evitese-um-erro-crasso-na-politica-de-drogas-deste-pais-1776533 (accessed 1 November 2017). 
Pullen, E., Oser, C. (2014), "Barriers to Substance Abuse Treatment in Rural and Urban Communities: Counselor Perspectives”, Substance Use \& Misuse, Vol. 49, No.7, pp. 891-901.

Robertson, E.B., David S.L., Rao, S.A. (2003), Preventing Drug Use among Children and Adolescents. A Research-Based Guide for Parents, Educators, and Community Leaders, National Institutes of Health. Retrieved from https://files. eric.ed.gov/fulltext/ED521530.pdf (accessed 30 April 2018).

Sajjadi, H., Harouni, G.G., Sani, M.S. (2015), "Personal, Familial and Environmental Determinants of Drug Abuse: a Causal-Comparative Study”, Global Journal of Health Science, Vol.7, No. 4, pp. 367-374.

SICAD (2016), Relatório Anual 2015 - A Situação do País em Matéria de Drogas e Toxicodependência, SICAD, Lisbon. Retrieved from http://www.sicad.pt/PT/ Publicacoes/Documents/Relat\%C3\%B3rio\%20Anual\%20Drogas\%20e\%20 Toxicodepend\%C3\%AAncias\%202015.pdf (accessed 30 April 2018).

Sumnall, H., Brotherhood, A. (2012), EMCDDA Insights. Social Reintegration and Employment: Evidence and Interventions for Drug Users in Treatment, European Monitoring Centre for Drugs and Drug Addiction, Publications Office of the European Union, Luxembourg.

Tripler Project (2017), Handbook on Social Reintegration of Recovered Drug Users. Retrieved from http://www.eurad.net/filestore/PDF/Handbook-on-social-reintegration-of-recovered-drug-users.pdf (accessed 1 May 2018).

UNESCO (2017), Good Policy and Practice in Health Education: Education Sector Responses to the Use of Alcohol, Tobacco and Drugs. Retrieved from http:// unesdoc.unesco.org/images/0024/002475/247509E.pdf (accessed 20 April 2018).

UNODC (2016), World Drug Report 2016, United Nations, New York.

UNODC (2017), World Drug Report 2017. Executive Summary: Conclusions and Policy Implications, United Nations.

U.S. Department of Health and Human Services (2016), Facing Addiction in America: The Surgeon General's Report on Alcohol, Drugs, and Health, HHS, Washington, DC. Retrieved from https://www.ncbi.nlm.nih.gov/books/NBK424857/ pdf/Bookshelf_NBK424857.pdf (accessed 23 April 2018).

Vonasch, A.J., Clark, C.J., Lau, S., Vohs, K.D., Baumeister, R.F. (2017), “Ordinary People Associate Addiction with Loss of Free Will”, Addictive Behaviors Reports, Vol. 5, pp. 56-66. 